\title{
Knowledge, Attitude and Practices Towards Cervical Cancer and its Screening Among Women from Tribal Population: a Community-Based Study from Southern India
}

\author{
Supriti Ghosh $^{1}$ (D) S Sneha D. Mallya ${ }^{2}$ (D) $\cdot$ Ranjitha S. Shetty $^{2,3}$ (D) Sanjay M. Pattanshetty $^{4}$ (D) Deeksha Pandey $^{5}$ (D) \\ Shama Prasada Kabekkodu ${ }^{1}$ (D) $\cdot$ Kapaettu Satyamoorthy ${ }^{1}$ (D) $\cdot$ Veena G. Kamath ${ }^{2}$ (D)
}

Received: 18 July 2019 / Revised: 18 February 2020 / Accepted: 23 March 2020 / Published online: 24 April 2020

(C) The Author(s) 2020

\begin{abstract}
Background Cervical cancer continues to be a leading cancer among women in India. Despite availability of various screening techniques, majority of Indian women remain unscreened for cancer cervix. The increasing incidence could be attributed to the lack of awareness regarding cervical cancer screening and paucity of organized screening facilities in the country. This study assessed the knowledge, attitude and practices (KAP) towards cervical cancer screening among tribal women of coastal Karnataka, southern India. Methods A community-based cross-sectional study was conducted among 1140 women aged 20-65 years from three tribes. Information on their KAP towards cervical cancer screening was collected using a semi-structured questionnaire.

Results Mean age of the participants was $39.8 \pm 10.1$ years. Although $82.9 \%$ of the participants reported to have heard of cervical cancer, $51 \%$ were aware that the disease could be prevented, and only $2.3 \%$ knew that it can be detected at an early stage. Over $75 \%$ of the participants did not have adequate knowledge regarding cervical cancer. However, majority of them (99.9\%) had a favourable attitude towards cervical cancer screening. None of them had undergone cervical cancer screening prior to the study. The knowledge scores were significantly associated with age group, marital status, education level, socioeconomic status and tribal community of the participants $(p<0.05)$.

Conclusion Overall knowledge regarding cervical cancer among the surveyed women was poor, though they exhibited a positive attitude. This calls for a sustained health education and screening program to create awareness and improve the uptake of cervical cancer screening among these women.
\end{abstract}

Keywords Cervical cancer $\cdot$ Reproductive health $\cdot$ Sexual health $\cdot$ Information $\cdot$ Universal access $\cdot$ Tribal women

Supriti Ghosh and Sneha D. Mallya contributed equally to this work.

Ranjitha S. Shetty

ranjitha.shetty@manipal.edu

1 Department of Cell and Molecular Biology, Manipal School of Life Sciences, Manipal Academy of Higher Education, Manipal, Karnataka 576104, India

2 Department of Community Medicine, Kasturba Medical College, Manipal Academy of Higher Education,

Manipal, Karnataka 576104, India

3 Centre for Indigenous Population, Kasturba Medical College, Manipal Academy of Higher Education,

Manipal, Karnataka 576104, India

4 Department of Health Policy, Prasanna School of Public Health, Manipal Academy of Higher Education, Manipal, Karnataka 576104, India

5 Department of Obstetrics and Gynaecology, Kasturba Medical College, Manipal Academy of Higher Education,

Manipal, Karnataka 576104, India

\section{Introduction}

The tribal population is an integral part of India's social diversity and has the second largest concentration after that of the African continent. They account for $8.6 \%$ of the total population of the country as per the 2011 census [1]. Among these, 75 tribes have been classified as particularly vulnerable tribal groups (PVTGs) based on preagriculture level of technology, stagnant or declining population, extremely low literacy and subsistence level of economy [2]. In Karnataka, Scheduled Tribes (ST) account for $6.95 \%$ (4.24 million) of the total state population [3]. Of the two PVTGs identified in the state of Karnataka, Koraga tribe predominantly inhabits Udupi and Dakshina Kannada districts located in the southern part of the state [2]. Marathi Naika and Malekudiya are the other two tribes residing in these districts. 
Poverty, illiteracy, meagre living conditions, lack of personal hygiene and poor health-seeking behaviour are known to be highly prevalent among these tribes. Further, early age at marriage, consanguinity, high parity and other behavioural factors among women in these tribal communities make them susceptible to sexually transmitted infections (STIs) [4-8].

Cancer cervix is the second most common cancer among women aged 15 to 44 years in India with an annual estimated incidence of 122,844 cases and mortality of 67,477 women [9]. Developing countries contribute to about $85 \%$, and India alone accounts for one fourth of the world's cervical cancer burden [10]. This is probably due to unavailability of nationwide regular cancer screening programs, lack of awareness and unwillingness of rural Indian women towards screening procedures for cancer cervix [11]. Being a part of tribal community, these aforementioned factors are expected to be widely prevalent among their women. In this direction, assessing their awareness regarding cervical cancer and its prevention is crucial. As there is paucity of such data from these tribes, especially Koraga women, the present study was undertaken with an aim to study their knowledge, attitude and practices towards cervical cancer, its causes, preventive measures and screening methods.

\section{Methods}

This community-based cross-sectional study was conducted from July 2014 to June 2017 among 1140 married women from Koraga, Malekudiya and Marathi Naika tribes of Udupi district, Karnataka, India. As a part of a study which included screening for cancer cervix and detection of cervical DNA virus infections among tribal women in this region, their knowledge, attitude and practices (KAP) towards cervical cancer were assessed [12]. The study team performed a door-to-door survey of the eligible tribal women. Upon obtaining written informed consent from all the willing participants, a pre-designed semi-structured questionnaire was administered to collect baseline demographic information and questions pertaining to knowledge, attitude and practice towards cervical cancer.

Eleven knowledge-related components were considered to calculate the cumulative knowledge score. These questions included knowledge about any risk factor of cervical cancer, preventive measure and early detection of the disease. The risk factor options included viral infection, early age at first sexual intercourse, multiple sexual partners, high parity, use of oral contraceptives, smoking, poor genital hygiene and condom use. Scoring for each correct answer was given +1 , incorrect answer was -1 , and "do not know" was scored 0 . Considering the distribution of knowledge scores among the study participants, cumulative score of 4 and above was categorized as adequate knowledge. Similar approach was undertaken to determine the cumulative attitude score. Three questions were considered for determining the attitude scores, viz. is cervical cancer screening important, should regular screening be made available at local health centres and willingness to be educated more about cervical cancer. Women with cumulative attitude score of 2 and above were considered to have favourable attitude towards cervical cancer screening. Women who had undergone Pap smear tests prior to the study were considered to follow fair practice towards cervical cancer screening.

Statistical Package for Social Sciences (SPSS) version 16 was used for data entry and analysis. Categorical data have been presented in frequencies and proportions. Univariable and multivariable logistic regressions were performed to estimate the strength of associations between knowledge score and socio-demographic variables of the participants and expressed as odds ratio (OR) and adjusted OR (AOR) with corresponding $95 \%$ confidence interval $(\mathrm{CI}) . p$ value $<0.05$ was considered statistically significant.

\section{Results}

The study comprised of 1140 women from three tribal communities aged between 20 and 65 years. Mean age of the participants was 39.8 years $(\mathrm{SD} \pm 10.1)$ with the majority of them being currently married (89.3\%). About $34 \%$ of the participants were illiterates, and only $5.1 \%$ had more than 10 years of schooling. Of the participants who were currently employed, $39.8 \%$ were engaged in unskilled type of work which included predominantly manual labour. Nearly two third of the study participants $(61.1 \%)$ were from low socioeconomic status, as determined by the modified Udai Pareek scale [13]. A total of $39.6 \%$ of the study participants belonged to Koraga and Malekudiya tribal communities, while the rest of them were from Marathi Naika community.

About 945 (82.9\%) study participants had heard about the term "cervical cancer," and hence, only they could answer the subsequent questions regarding cervical cancer. Their knowledge and attitude about cervical cancer and screening are summarized in Table 1. Of these 945 women, 51.0\% reported to know that the disease is preventable, though majority (97.7\%) were ignorant about the fact that cervical cancer can be detected at an early stage. Only $7.0 \%$ of the participants knew about viral infection being a risk factor for the development of cervical cancer, and about $3.6 \%$ of the participants had a misconception that use of condom causes cervical cancer. A total of $19(2.0 \%)$ women said Papanicolaou (Pap) test could be used for detection of cervical cancer, while only one participant mentioned biopsy as a detection tool. Source of information regarding cervical cancer claimed to be was mostly through relatives and friends $(97.1 \%)$, while print and electronic media (TV, radio, newspaper) contributed to about $65.8 \%$, and medical and health professionals contributed to a little over $32 \%$ of the information. However, it was positive to note that over $95 \%$ of the participants considered cervical cancer screening 
Table 1 Knowledge and attitude of the study participants about cervical cancer and screening $(n=945)$

\begin{tabular}{ll}
\hline & Frequency $(\%)$ \\
\hline Knowledge-related components & \\
Risk factors for development of cervical cancer \\
Poor genital hygiene & $361(38.2)$ \\
Early age at sexual intercourse & $271(26.7)$ \\
Smoking & $157(16.6)$ \\
High parity & $111(11.6)$ \\
Use of oral contraceptives & $81(8.6)$ \\
Multiple sexual partners & $69(7.3)$ \\
Viral infection & $66(7.0)$ \\
Condom use & $34(3.6)$ \\
Do not know & $467(49.4)$ \\
Whether cervical cancer prevention is possible \\
Yes & $482(51.0)$ \\
No & $455(48.1)$ \\
Do not know & $8(0.8)$ \\
Whether detection of this disease is possible at an early stage \\
Do not know & $923(97.7)$ \\
Yes & $22(2.3)$ \\
Source of information & \\
Relatives or friends & $943(9.2)$ \\
Mass media &
\end{tabular}

tests to be important and agreed that regular screening services should be made available in the health centres which cater to rural and remote areas. They also wanted to be educated more about cervical cancer by the healthcare professionals.

Table 2 shows the knowledge, attitude and practice scores of the participants. About $77 \%$ of the participants had inadequate knowledge regarding cervical cancer prevention and screening. While almost everyone $(99.1 \%$ ) had a favourable attitude towards getting screened for cervical cancer if the services are made available, none of them had undergone any screening tests for detection of pre-malignant/malignant lesions of the cervix in the past.

Association of cumulative knowledge scores of the participants with their socio-demographic profile is summarized in Table 3. Of the 945 women who had answered these
Table 2 Knowledge, attitude and practice score of the participants $(n=$ 945)

\begin{tabular}{llll}
\hline Items & Values & $p$ value & $95 \%$ CI \\
\hline Knowledge score & & & \\
Adequate & $212(22.4)$ & $<0.0001$ & $50.98-58.51$ \\
Inadequate & $733(77.6)$ & & \\
Mean score & $1.70 \pm 1.89$ & & \\
Range of score & $0-7$ & & \\
Attitude score & & & \\
Favourable & $944(99.9)$ & $<0.0001$ & \\
Unfavourable & $1(0.1)$ & & \\
Mean score & $2.96 \pm 0.21$ & & \\
Range of score & $1-3$ & & \\
Practice & & $<0.0001$ & \\
Yes & 0 & \\
No & $945(100.0)$ & \\
\hline
\end{tabular}

Values have been represented as frequency (\%) or mean \pm standard deviation

questions, women with inadequate knowledge were more likely to be those aged $>31$ years (odds ratio $(O R)=1.94$, 95\% CI 1.40-2.70), widowed or separated women $(\mathrm{OR}=$ 3.96 , 95\% CI 1.65-8.99) and women with no primary level of education (OR $=19.10,95 \%$ CI 11.4-32.06). Similarly, a significant association was observed between knowledge inadequacy and low socio-economic status (OR $=4.53,95 \% \mathrm{CI}$ 3.24-6.33) and Koraga and Malekudiya tribal community $(\mathrm{OR}=3.25,95 \%$ CI 2.24-4.71). Interestingly, women who were employed showed about 0.4 times lesser knowledge score than home-makers $(\mathrm{OR}=0.59,95 \%$ CI $0.43-0.80)$.

Multivariable logistic regression analysis mutually adjusted for all the six socio-demographic variables showed that women with low level of education ( $\mathrm{AOR}=15.49,95 \%$ CI 9.10-26.36), low socio-economic status ( $\mathrm{AOR}=1.81 ; 95 \% \mathrm{CI} 1.22-2.68)$ and those belonging to Koraga and Malekudiya communities were more likely to be lacking knowledge about cervical cancer, its prevention and early detection.

\section{Discussion}

Our study population had a suboptimal level of knowledge regarding cervical cancer and its prevention. Encouragingly, they showed a favourable attitude towards cancer screening and acceptance towards cancer education.

In this study, $82.9 \%$ participants had heard of cervical cancer which is similar to a report from Qatar $(85.0 \%)$ and Cambodia $(74 \%)$ and higher than that reported in Korea, Nepal and India where it ranged between 60 and $66 \%$ [14-18]. Although a little more than half of the study population $(51.0 \%)$ knew that cervical cancer is preventable, only 
Table 3 Association of knowledge adequacy with the socio-demographic profile of the study population $(n=945)$

\begin{tabular}{|c|c|c|c|c|c|c|}
\hline \multirow{2}{*}{$\begin{array}{l}\text { Socio-demographic } \\
\text { characteristics }\end{array}$} & \multicolumn{2}{|l|}{ Frequency $(\%)$} & \multicolumn{4}{|l|}{ OR $(95 \% \mathrm{CI})$} \\
\hline & $\begin{array}{l}\text { Knowledge inadequate } \\
(n=733)\end{array}$ & $\begin{array}{l}\text { Knowledge adequate } \\
(n=212)\end{array}$ & Crude OR & $p$ value & Adjusted OR & $p$ value \\
\hline \multicolumn{7}{|l|}{ Age (in years) } \\
\hline$\leq 30(n=247)$ & $169(68.4)$ & $78(31.6)$ & 1.00 & $<0.0001$ & 1.00 & 0.14 \\
\hline$>30(n=698)$ & $564(80.8)$ & $134(19.2)$ & $1.94(1.40-2.70)$ & & $1.34(0.91-1.98)$ & \\
\hline \multicolumn{7}{|l|}{ Marital status } \\
\hline Married $(n=865)$ & $659(76.2)$ & $206(23.8)$ & 1.00 & 0.001 & 1.00 & 0.26 \\
\hline Widowed/separated $(n=80)$ & $74(92.5)$ & $6(7.5)$ & $3.86(1.65-8.99)$ & & $1.70(0.67-4.34)$ & \\
\hline \multicolumn{7}{|l|}{ Years of schooling } \\
\hline Nil to primary level $(n=475)$ & $458(96.4)$ & $17(3.6)$ & $\begin{array}{l}19.10 \\
\quad(11.4-32.06)\end{array}$ & $<0.0001$ & $\begin{array}{l}15.49 \\
\quad(9.10-26.36)\end{array}$ & $<0.0001$ \\
\hline $\begin{array}{l}\text { Middle school and above } \\
(n=470)\end{array}$ & $275(58.5)$ & $195(41.5)$ & 1.00 & & 1.00 & \\
\hline \multicolumn{7}{|l|}{ Occupation } \\
\hline Employed $(n=429)$ & $354(82.5)$ & $75(17.5)$ & 1.00 & 0.001 & 1.00 & 0.49 \\
\hline Home-maker $(n=516)$ & $379(73.4)$ & $137(26.6)$ & $0.59(0.43-0.80)$ & & $1.14(0.78-1.67)$ & \\
\hline \multicolumn{7}{|l|}{ Socio-economic status } \\
\hline Low $(n=535)$ & $474(88.6)$ & $61(11.4)$ & $4.53(3.24-6.33)$ & $<0.0001$ & $1.81(1.22-2.68)$ & 0.003 \\
\hline Medium $(n=410)$ & $259(63.2)$ & $151(36.8)$ & 1.00 & & 1.00 & \\
\hline \multicolumn{7}{|l|}{ Tribal community } \\
\hline $\begin{array}{l}\text { Koraga and Malekudiya } \\
\qquad(n=362)\end{array}$ & $321(88.7)$ & $41(11.3)$ & $3.25(2.24-4.71)$ & $<0.0001$ & $2.14(1.37-3.35)$ & 0.001 \\
\hline Marathi Naika $(n=583)$ & $412(70.7)$ & $171(29.3)$ & 1.00 & & 1.00 & \\
\hline
\end{tabular}

$2.3 \%$ of them were aware that the disease can be detected at an early stage. This is in contrast to the findings reported from Delhi (India), Ethiopia and Zimbabwe in which a higher level of knowledge was exhibited by the women [19-21]. This could be attributed to the difference in the nature of population studied and study settings. However, the results of our study are in agreement with that of previous studies from India in which majority (81.9-96.5\%) of the women had poor knowledge [22-25]. As per previous published literature, lack of knowledge among women in the developing countries towards cervical cancer is mostly attributed to the paucity of organized cancer screening programs, sociocultural barriers and inefficient media campaigns in creating awareness [26].

In the present study, poor genital hygiene (38.2\%) and early age at sexual intercourse (26.7\%) were the most commonly quoted risk factors. However, in a study conducted in rural Kerala by Aswathi et al., a very small proportion of women were aware that poor genital hygiene (3.9\%) and having multiple sexual partners $(1.6 \%)$ are risk factors for cervical cancer [27]. In our study, knowledge regarding etiological role of viral infections in cervical cancer was very dismal (7.0\%) compared with that of a study done by Arunadevi et al. in Tamil Nadu which reported a slightly higher proportion (13\%) of women being aware about it [28].

Almost half of our study population (49.4\%) were unaware about any of the risk factors for cervical cancer, while only
$27.9 \%$ of the women in a study conducted in Cambodia, and $11 \%$ in another Indian study did not know about the risk factors $[15,28]$. This difference could be due to low literacy and ignorance which were highly prevalent among our study population.

On assessing their attitude towards prevention of cancer cervix, majority (>90\%) of tribal women exhibited favourable attitude which is in contrast to the findings reported in previous Indian studies from Bhopal conducted by Bansal et al. $(80.5 \%)$ and in Andhra Pradesh by Narayana G et al. $(62.5 \%)$, though the way of assessment of attitudes varied widely $[29,30]$.

None of our study population had ever undergone screening test for cancer cervix prior to the survey. However, many community-based studies from Cambodia, Nepal and Ethiopia $[15,17,18]$ reported a small proportion of women being screened for cancer cervix with Pap test (ranged from 7.1 to $13.6 \%$ ) and so did the previously published Indian studies (6.9-13.4\%) [18, 27, 30]. Poor cancer screening practice among the study population could be explained by their poor health-seeking behaviour and non-availability of organized cancer screening facilities in remote areas.

In the present study, predominant source of information regarding cervical cancer was family and friends (97.1\%) followed by mass media $(65.8 \%)$ and healthcare workers $(23 \%)$. On the other hand, media was reported as the most 
common source of information on cervical cancer by many of the earlier studies $[15,28,30,31]$. It was worthwhile to observe that over $88 \%$ of the participants thought cervical cancer screening was important and over 99\% opined that regular screening services should be made available in their areas. Moreover, women were found to have favourable attitude despite the poor knowledge and practices towards cervical cancer prevention in our study. This finding is consistent with the result of studies done by Bansal et al. from Bhopal and Shreshta et al. and Thapa et al. from Nepal [17, 29, 32].

On assessing the association of cumulative knowledge score with age of the study population, younger women (30 years or less) were observed to have higher scores which is in contrast to the previously published studies where direct proportionality of age with better knowledge was reported [17-19]. The higher levels of knowledge among the participants with younger age could be due to the availability and ease of accessibility of information in this era of information technology. Women with higher literacy level were found to be significantly associated with better knowledge which is similar to the findings of previously published studies $[14,17]$. Women who were employed were observed to lack adequate knowledge than those who were homemakers. This contradicts the findings of a study conducted by AlMeer et al. in Qatar [14]. Since no significant difference was observed in the source of information among employed and home-makers, the data warrants further investigation. Women with better socio-economic status displayed better knowledge scores in the study. This is in concordance with the study by Narayan et al., wherein participants with low household income exhibited poor knowledge and unfavourable attitude towards cervical cancer screening [30]. Moreover, knowledge scores among women from the Koraga and Malekudiya tribal communities combined were significantly poorer as compared with those from Marathi Naika community. This could be due to the fact that people from Marathi Naika community have been receiving better formal education and employment in recent years and progressing towards the mainstream population.

This is a first of its kind community-based survey, to the best of authors' knowledge, conducted to study the KAP towards cervical cancer among tribal women in the coastal region of southern India. This data provides pertinent information for designing appropriate interventions to improve cervical cancer awareness and screening practices among the vulnerable populations. However, due to the cross-sectional nature of our study, we might not have been able to elucidate all the determinants of KAP towards cervical cancer among these women.

\section{Conclusion}

As observed in the study, there is a considerable lack of knowledge and practices towards cervical cancer and its screening among the tribal women of this region, though they had a favourable attitude. The study identified that being an illiterate or a school drop-out, having low socio-economic status and belonging to Koraga and Malekudiya tribal communities were the significant predictors for lack of knowledge towards cervical cancer among tribal women. Hence, there is a need for wellorganized cancer education programs to create awareness and to eliminate misconceptions regarding prevention of cervical cancer in this community. In addition, provision of comprehensive cancer screening facilities at primary care level would improve the cervical cancer screening practices among these vulnerable populations. Further qualitative studies are essential to understand the prevailing barriers regarding cervical cancer screening among tribal women in this region.

Acknowledgements Open access funding provided by Manipal Academy of Higher Education, Manipal. The authors express their gratitude towards the District Health and Family Welfare Department and Integrated Tribal Development Project (ITDP), Udupi, for their support. The authors are grateful to the dedicated study nurse Mrs. Singari and other support staff at MAHE and to the participants of the study for their active involvement in the study.

Authors' Contributions Ranjitha S Shetty, Sneha D Mallya, Sanjay M Pattanshetty, Veena G Kamath, Shama Prasada Kabekkodu, Deeksha Pandey and Kapaettu Satyamoorthy collaborated in the conceptualization and designing of the study including writing and revising the study protocol. Supriti Ghosh, Ranjitha S Shetty and Sneha D Mallya were involved in data acquisition, analysis, interpretation and preparation of manuscript. All the authors have contributed in the manuscript revision and read and approved the final version for publication.

Funding Information This work was supported by the Indian Council of Medical Research (ICMR), New Delhi, India (grant no. TRIBAL/70/ 2013-ECD-II), awarded to Ranjitha S Shetty and the Department of Science and Technology (DST)- Innovation in Science Pursuit for Inspired Research (INSPIRE) fellowship (IF150647), Government of India, to Supriti Ghosh.

\section{Compliance with Ethical Standards}

Conflict of Interest The authors declare that they have no conflict of interest.

Permissions Prior permissions were obtained from the Integrated Tribal Development Project (ITDP), Udupi, and District Health and Family Welfare Department, Udupi, Karnataka, for carrying out this study among tribal populations.

Ethical Approval The study was approved by the Kasturba Hospital (KH) - Institutional Ethics Committee, Kasturba Medical College, Manipal (Registration no: ECR/146/Inst/KA/2013; Project Approval No.: IEC - 181/2013), prior to initiation of the study.

Informed Consent Written informed consent was obtained from all the participants included in the study.

Open Access This article is licensed under a Creative Commons Attribution 4.0 International License, which permits use, sharing, adaptation, distribution and reproduction in any medium or format, as long as you give appropriate credit to the original author(s) and the source, 
provide a link to the Creative Commons licence, and indicate if changes were made. The images or other third party material in this article are included in the article's Creative Commons licence, unless indicated otherwise in a credit line to the material. If material is not included in the article's Creative Commons licence and your intended use is not permitted by statutory regulation or exceeds the permitted use, you will need to obtain permission directly from the copyright holder. To view a copy of this licence, visit http://creativecommons.org/licenses/by/4.0/.

\section{References}

1. Government of India. Census 2011. Accessed 7 Dec 2017. Available from: http://censusindia.gov.in/2011census/population enumeration.aspx.

2. Sabar B. Food insecurity and coping strategies: a tale of two particularly vulnerable tribal groups in Karnataka. J Asian Afr Stud. 2016;51:718-41.

3. Roy S, Hegde HV, Bhattacharya D, Upadhya V, Kholkute SD. Tribes in Karnataka: status of health research. Indian J Med Res. 2015;141:673-87.

4. Basu S. Dimensions of tribal health in India. Health Popul Perspect Issues. 2000;20:61-70.

5. Bala SM, Thiruselvakumar D. Overcoming problems in the practice of public health among tribals of India. Indian J Community Med. 2009;34:283-7.

6. Agrawal PK, Agrawal S. To what extent are the indigenous women of Jharkhand, India living in disadvantageous conditions: findings from India's National Family Health Survey. Asian Ethn. 2010;11:61-80.

7. Shivaprasad HS, Gangadhar MR, Komala M, Malini SS. Awareness and significance of health, sexual diseases, genetic disorders and dietetic issues among tribal women of India. World $\mathbf{J}$ Life Sci Med Res. 2011;1:99-104.

8. Rao VG, Saha KB, Bhat J, Tiwary BK, Abbad A. Exploring knowledge and healthseeking behaviour related to sexually transmitted infections among the tribal population of Madhya Pradesh, Central India. J Biosoc Sci. 2012;44:625-9.

9. Bruni L, Albero G, Serrano B, Mena M, Gómez D, Muñoz J, et al. Human papillomavirus and related diseases in India. Summary report 19 April 2017. In: ICO/IARC Information Centre on Papillomavirus and Cancer (HPV Information Centre) 2017. http://www.hpvcentre.net/ statistics/reports/IND_FS.pdf. Accessed 30 May 2018.

10. Bray F, Ferlay J, Soerjomataram I, Siegel RL, Torre LA, Jemal A. Global cancer statistics 2018: GLOBOCAN estimates of incidence and mortality worldwide for 36 cancers in 185 countries. CA Cancer J Clin. 2018;68:394-424.

11. Sankaranarayanan R, Nene BM, Shastri SS, Jayant K, Muwonge R, Budukh AM, et al. HPV screening for cervical cancer in rural India. N Engl J Med. 2009;360:1385-94.

12. Ghosh S, Shetty RS, Pattanshetty SM, Mallya SD, Pandey D, Kabekkodu SP, et al. Human papilloma and other DNA virus infections of the cervix: a population based comparative study among tribal and general population in India. PLoS One. 2019;14: e0219173.

13. Pareek U, Trivedi G. Delhi: Manasayan manual of socioeconomic status (rural). 1981.

14. Al-Meer FM, Aseel MT, Al-Khalaf J, Al-Kuwari MG, Ismail MFS. Knowledge, attitude and practices regarding cervical cancer and screening among women visiting primary health care in Qatar. East Mediterr Health J. 2011;17:855-61.

15. Touch S, Oh J-K. Knowledge, attitudes, and practices toward cervical cancer prevention among women in Kampong Speu Province, Cambodia. BMC Cancer. 2018;18:294.
16. Tran NT, Choe SI, Taylor R, Ko WS, Pyo HS, So HC. Knowledge, attitude and practice (KAP) concerning cervical cancer and screening among rural and urban women in six provinces of the democratic People's Republic of Korea. Asian Pac J Cancer Prev. 2011;12:3029-33.

17. Shrestha J, Saha R, Tripathi N. Knowledge, attitude and practice regarding cervical cancer screening amongst women visiting tertiary centre in Kathmandu, Nepal. Nepal J Med Sci. 2013;2:85-90.

18. Ramaiah R, Jayarama S. Knowledge, attitude and practices about cervical cancer among rural married women: a cross sectional study. Int J Commun Med Public Heal. 2018;5:1466.

19. Singh M, Ranjan R, Das B, Gupta K. Knowledge, attitude and practice of cervical cancer screening in women visiting a tertiary care hospital of Delhi. Indian J Cancer. 2014;51:319-23.

20. Aweke YH, Ayanto SY, Ersado TL. Knowledge, attitude and practice for cervical cancer prevention and control among women of childbearing age in Hossana town, Hadiya zone, Southern Ethiopia: communitybased cross-sectional study. PLoS One. 2017;12:e0181415.

21. Mutambara J, Mutandwa P, Mahapa M, Chirasha V, Nkiwane S, Shangahaidonhi T. Knowledge, attitudes and practices of cervical cancer screening among women who attend traditional churches in Zimbabwe. J Cancer Res Pract. 2017;4:53-8.

22. Roy B, Tang TS. Cervical cancer screening in Kolkata, India: beliefs and predictors of cervical cancer screening among women attending a Women's Health Clinic in Kolkata, India. J Cancer Educ. 2008;23:253-9.

23. Ashwini NU, Murthy SN, Swarup A, Dutt V, Muthukumar V. Current knowledge, attitude, and practice about cervical cancer among rural Indian women. Int J Med Sci Public Health. 2016;5:1554-9.

24. Sabeena S, Bhat PV, Kamath V, Aswathyraj S, Arunkumar G. Knowledge, attitude and practice concerning human papilloma virus infection and its health effects among rural women, Karnataka, South India. Asian Pac J Cancer Prev. 2015;16:5053-8.

25. Kumar HH, Tanya S. A study on knowledge and screening for cervical cancer among women in Mangalore City. Ann Med Health Sci Res. 2014;4:751-6.

26. Devarapalli P, Labani S, Nagarjuna N, Panchal P, Asthana S. Barriers affecting uptake of cervical cancer screening in low and middle income countries: a systematic review. Indian J Cancer. 2018;55:318-26.

27. Aswathy S, Quereshi MA, Kurian B, Leelamoni K. Cervical cancer screening: current knowledge \& practice among women in a rural population of Kerala, India. Indian J Med Res. 2012;136:205-10.

28. Arunadevi V, Prasad G. Knowledge and awareness of cervical cancer among women in rural India. Int J Cur Res Rev. 2015;7:29.

29. Bansal AB, Pakhare AP, Kapoor N, Mehrotra R, Kokane AM. Knowledge, attitude, and practices related to cervical cancer among adult women: a hospital-based cross-sectional study. J Nat Sci Biol Med. 2015;6:324-8.

30. Narayana G, Suchitra MJ, Sunanda G, Ramaiah JD, Kumar BP, Veerabhadrappa K. Knowledge, attitude, and practice toward cervical cancer among women attending Obstetrics and Gynecology Department: a cross-sectional, hospital-based survey in South India. Indian J Cancer. 2017;54:481.

31. Veerakumar AM. Knowledge of carcinoma cervix among rural women of reproductive age in Trichy district, India. J Compr Health. 2017;5:46.

32. Thapa N, Maharjan M, Petrini MA, Shah R, Shah S, Maharjan N, et al. Knowledge, attitude, practice and barriers of cervical cancer screening among women living in mid-western rural, Nepal. J Gynecol Oncol. 2018;29:e57.

Publisher's Note Springer Nature remains neutral with regard to jurisdictional claims in published maps and institutional affiliations. 